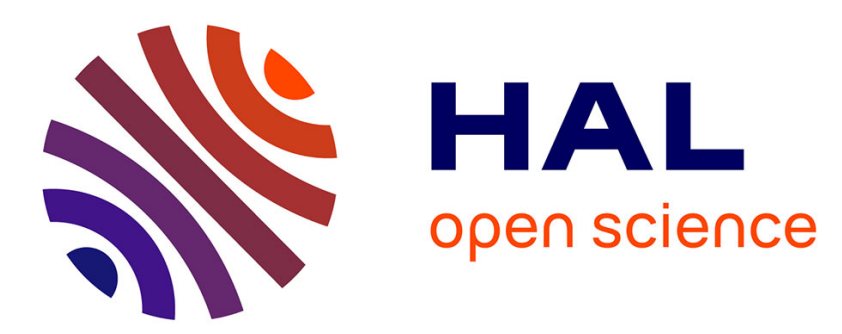

\title{
A new mathematical model for combining growth and energy intake in animals: The case of the growing pig
}

\author{
A.B. Strathe, H. Sørensen, A. Danfær
}

\section{To cite this version:}

A.B. Strathe, H. Sørensen, A. Danfær. A new mathematical model for combining growth and energy intake in animals: The case of the growing pig. Journal of Theoretical Biology, 2009, 261 (2), pp.165. 10.1016/j.jtbi.2009.07.039 . hal-00559151

\section{HAL Id: hal-00559151 \\ https://hal.science/hal-00559151}

Submitted on 25 Jan 2011

HAL is a multi-disciplinary open access archive for the deposit and dissemination of scientific research documents, whether they are published or not. The documents may come from teaching and research institutions in France or abroad, or from public or private research centers.
L'archive ouverte pluridisciplinaire HAL, est destinée au dépôt et à la diffusion de documents scientifiques de niveau recherche, publiés ou non, émanant des établissements d'enseignement et de recherche français ou étrangers, des laboratoires publics ou privés. 


\title{
Author's Accepted Manuscript
}

A new mathematical model for combining growth and energy intake in animals: The case of the growing pig

\author{
A.B. Strathe, H. Sørensen, A. Danfær
}

PII:

S0022-5193(09)00351-8

DOI:

doi:10.1016/j.jtbi.2009.07.039

Reference:

YJTBI 5656

To appear in:

Journal of Theoretical Biology

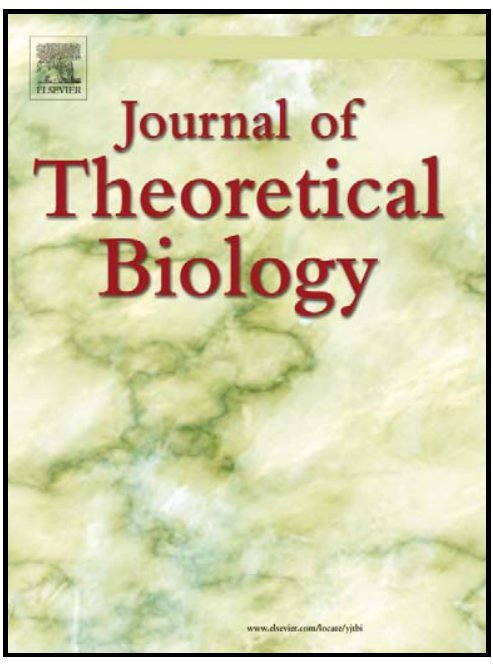

www.elsevier.com/locate/yjtbi

Received date: 23 October 2008

Revised date: $\quad 20$ July 2009

Accepted date: $\quad 30$ July 2009

Cite this article as: A.B. Strathe, H. Sørensen and A. Danfær, A new mathematical model for combining growth and energy intake in animals: The case of the growing pig, Journal of Theoretical Biology, doi:10.1016/j.jtbi.2009.07.039

This is a PDF file of an unedited manuscript that has been accepted for publication. As a service to our customers we are providing this early version of the manuscript. The manuscript will undergo copyediting, typesetting, and review of the resulting galley proof before it is published in its final citable form. Please note that during the production process errors may be discovered which could affect the content, and all legal disclaimers that apply to the journal pertain. 
A new mathematical model for combining growth and energy intake in animals: The case of the growing pig

A. B. Strathe $e^{a, b^{*}}$, H. Sørensen ${ }^{c}$, and A. Danfær ${ }^{a}$

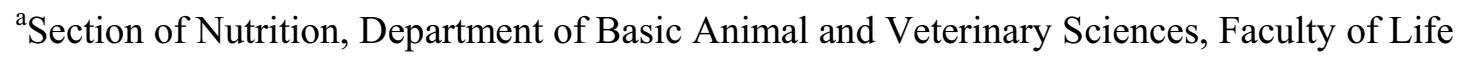

Sciences, University of Copenhagen, DK-1870, Frederiksberg, Denmark

${ }^{\mathrm{b}}$ Animal Health, Welfare and Nutrition, Faculty of Agricultural Sciences, Blichers Allé 20, DK8830 Tjele, Denmark

${ }^{\mathrm{c}}$ Department of Mathematical Sciences, University of Copenhagen, Universitetsparken 5, DK-2100 Copenhagen $\varnothing$, Denmark

Corresponding author:

A. B. Strathe

Email: strathe@,life.ku.dk

Phone: +4540621060

Fax: +45 89991525

\section{Abstract}


A simultaneous model for analysis of net energy intake and growth curves is presented, viewing the animal's responses as a two-dimensional outcome. The model is derived from four assumptions: 1) the intake is a quadratic function of metabolic weight; 2) the rate of body energy accretion represents the difference between intake and maintenance; 3) the relationship between body weight and body energy is allometric and 4) animal intrinsic variability affects the outcomes so the intake and growth trajectories are realizations of a stochastic process. Data on cumulated net energy intake and body weight measurements registered from weaning to maturity were available for 13 pigs. The model was fitted separately to 13 datasets. Furthermore, slaughter data obtained from 170 littermates was available for validation of the model. The parameters of the model were estimated by maximum likelihood within a stochastic state space model framework where a transform-bothsides approach was adopted to obtain constant variance. A suitable autocorrelation structure was generated by the stochastic process formulation. The pigs' capacity for intake and growth were quantified by eight parameters: body weight at maximum rate of intake (149 - $281 \mathrm{~kg})$; maximum rate of intake (25.7 - 35.7 MJ/day); metabolic body size exponent (fixed: 0.75); the daily maintenance requirement per $\mathrm{kg}$ metabolic body size $\left(0.232-0.303 \mathrm{MJ} /\left(\right.\right.$ day $\left.\left.\times \mathrm{kg}^{0.75}\right)\right)$; reciprocal scaled energy density $\left(0.192-0.641 \mathrm{~kg} / \mathrm{MJ}^{\theta_{6}}\right)$; a dimensional exponent, $\theta_{6}(0.730-0.867)$; coefficient for animal intrinsic variability in intake $\left(0.120-0.248 \mathrm{MJ}^{0.5}\right)$ and coefficient for animal intrinsic variability in growth $\left(0.029-0.065 \mathrm{~kg}^{0.5}\right)$. Model parameter values for maintenance requirements and body energy gains were in good agreement with those obtained from slaughter data. In conclusion, the model provides biologically relevant parameter values, which cannot be derived by traditional analysis of growth and energy intake data.

\section{Keywords: Growth, Energy intake, Pigs, Stochastic differential equations}




\section{Introduction}

Growth in animals has been studied for centuries both from a biological and a mathematical view point and many growth functions are available (France and Thornley, 1984). These functions are especially valuable if growth and energy intake are studied for long periods of time where nonlinearities are visually detectable in data, i.e. sigmoid shapes and diminishing return behaviours. Analysis of intake and growth data is usual done separately by fitting nonlinear functions of time (Kanis and Koop, 1990; Lopez et al., 2000). Another approach for modelling growth and intake curves in animals is to describe the body weight $(B W)$ as function of the cumulated intake (Andersen and Pedersen, 1996). This has an advantage because the efficiency of 
utilizing nutrients for growth follows directly as the derivative with respect to intake (Andersen and Pedersen, 1996). Growth and intake processes are interrelated because it can be assumed that the animal grows as a consequence of the nutrients and energy consumed (push effect) or it eats to meet the demands of its growth potential (pull effect) (Emmans, 1997). Simultaneous modelling of growth and energy intake offers the possibility to formulate a mathematical model where the equations are linked so that more detailed information is extracted, e.g. maximum intake rate, maintenance requirements, body energy $(B E)$ accretion. If complete records of growth and energy intake trajectories from individual animals are available, estimation of model parameters could be possible. In the following, we define dietary energy as net energy because net energy systems are currently the recommended energy evaluation system for formulating diets for growing mammals (Just, 1982; Noblet et al., 1994a; NRC, 2000).

Models in animal biology have usually been defined in terms of ordinary differential equations (ODEs) (France and Thornley, 1984). Another option is to use stochastic differential equations (SDEs). The main attraction of the SDEs and the primary difference to the corresponding ODEs is the inclusion of a diffusion term which accounts for model uncertainty. Model uncertainty is biological meaningful because there are many factors affecting intrinsic growth processes which cannot be explicitly modelled. Modelling growth and intake processes using SDE models provides the possibility of quantifying both the trend and variation in the processes. Furthermore, using SDE models instead of ODE models is a powerful approach to deal with serially correlated residuals that are likely to occur when analysing growth data (Sandland and McGilchrist, 1979; Garcia, 1983).

The objective of the present study is to develop a mathematical model for simultaneous analysis of serial net energy intake and BW measurements. From these easily obtainable data, the model should quantify the dynamics of growth and yield information on energy intake capacity, maintenance requirements and body energy gain.

\section{Material and methods}




\subsection{Animals and diets}

The data used in this analysis is part of a serial slaughter experiment set up to determine growth capacity, energy and nutrient utilization in growing pigs (Danfær and Fernandez, in preparation). A total of 183 pigs participated in the experiment. Data on intake and growth from 13 of these pigs were used in the present paper to estimate the parameters of the proposed model. The experiment was set up as a fully randomized block design with three blocks and six different treatment groups. Each experimental group referred to a combination of two factors, i.e. gender (male, female and castrate) and a genetic sub-index for feed efficiency (high and medium level). The experimental pigs used in this study were crosses of YL sows (Landrace and Yorksire) and Duroc boars. The pigs were fed seven highly nutritious diets in the corresponding intervals: 4-7 weeks, 7 weeks-25 kg, 25 $45 \mathrm{~kg}, 45-65 \mathrm{~kg}, 65-100 \mathrm{~kg}, 100-150 \mathrm{~kg}$ and $150 \mathrm{~kg}$ to maturity. The chemical composition of the seven diets is presented in Table 1 . The pigs were housed individually under thermoneutral conditions and given ad libitum access to feed during the entire growth period to maximize growth. All pigs were weighed at birth, weaning, weekly until approximately $150 \mathrm{~kg} B W$ and then every second week until the time of slaughter. The cumulated feed intake was record twice weekly from feed dispensers and is summarized to the corresponding dates of $B W$ measurement. The total net energy intake is calculated as the net energy content of the diets (Table 1) multiplied by the cumulated feed intake in the corresponding periods of use. For the present analysis, we assume that the methods for prediction of net energy contents of the seven diets (Just, 1982; Boisen and Fernandez, 1997) are valid in the entire growth period from $7-450 \mathrm{~kg} B W$. This is somewhat simplistic, but is nevertheless supported by the findings of Noblet et al. (1994b). After slaughter, the chemical composition and energy content of the body was determined (Danfær and Fernandez, in preparation).

Insert Table 1.

\subsection{Mathematical derivation of the growth model}


In the following, we assume that animal growth and feed intake are driven by the state of the animal, which is described by the state variable $B W$ (France and Thornley, 1984). Furthermore, it is assumed that allometry $\left(Y \propto X^{a}\right)$ can describe the differential growth of $B W$ and $B E$. Note that the augmented allometric function may for some traits or data sets provide at better description (Schinckel and de Lange, 1996); however, parameter identifiability is a key issue in statistical modelling and therefore the simpler allometric function is adopted. Suppose that rate of total net energy intake $(N E)$ is a quadratic function of the metabolic body weight

$$
\frac{d N E}{d t}=\theta_{1} \times B W^{\theta_{3}}-\theta_{2} \times B W^{2 \times \theta_{3}}
$$

where $\theta_{1}, \theta_{2}, \theta_{3}$ are parameters. This functional relationship (1) has previously been used to describe protein accretion curves in boars of different breed (Tauson et al., 1998). The assumption that ingestion rate is a function of metabolic body size has also been used in dynamic energy budget models in animal ecology (Nisbet et al., 2000). Using the above function (1) implies that the rate of intake is symmetric in $B W$, but it does not imply that the rate of intake is symmetric in time because the growth rate is not constant over time. Using a quadratic function of metabolic size for modelling the rate of intake allows to parameterize the model in terms of the maximum rate of intake $\left(\theta_{2}{ }^{*}\right)$ and the $B W$ at which the maximum rate $\left(\theta_{l}^{*}\right)$ occurs. There are several advantages to reparameterize the model because the new parameters can be assigned biological meaning and reduce the intracorrelation between the two parameter estimates. The new parameters can be derived by differentiation of (1) with respect to $B W$

$$
\frac{d N E / d t}{d B W}=\frac{\theta_{1} B W^{\theta_{3}} \theta_{3}}{B W}-\frac{2 \theta_{2} B W^{2 \theta_{3}} \theta_{3}}{B W}
$$

and setting (2) equal to zero and solving (2) with respect to $B W$. This yields the $B W$ at which intake is maximized and corresponding rate of intake, i.e.,

$$
\begin{aligned}
& \theta_{1}^{*}=\left(\frac{\theta_{1}}{2 \theta_{2}}\right)^{1 / \theta_{3}} \\
& \theta_{2}^{*}=\theta_{1} \times\left(\frac{\theta_{1}}{2 \theta_{2}}\right)-\theta_{2} \times\left(\frac{\theta_{1}}{2 \theta_{2}}\right)^{2}=\frac{\theta_{1}^{2}}{4 \theta_{2}}
\end{aligned}
$$


In order to reparameterize the model we need to express the parameters $\theta_{1}$ and $\theta_{2}$ as functions of $\theta_{1}{ }^{*}$ and $\theta_{2}{ }^{*}$, i.e. to solve (3) with respect to $\theta_{1}$ and $\theta_{2}$ :

$$
\begin{aligned}
& \theta_{1}=\frac{2 \theta_{2}^{*}}{\left(\theta_{1}^{*}\right)^{\theta_{3}}} \\
& \theta_{2}=\frac{\theta_{2}^{*}}{\left(\theta_{1}^{*}\right)^{2 \theta_{3}}}
\end{aligned}
$$

which can be inserted into (1).

The increment in $B E$ represents the difference between net energy intake and net energy for maintenance, and the rate of $B E$ accretion can be written as follows:

$$
\frac{d B E}{d t}=\frac{d N E}{d t}-\theta_{4} \times B W^{\theta_{3}}=\left(\theta_{1}-\theta_{4}\right) \times B W^{\theta_{3}}-\theta_{2} \times B W^{2 \times \theta_{3}}
$$

where $\theta_{4}$ is the maintenance energy requirement scaled to metabolic body size. The growth function derived here is without any assumption of an upper limit for the size of the animal. Since the mature size of an animal is an important biological growth parameter, the proposed growth model should accommodate calculation of such a trait. The basic idea built into the model is that the rate of intake approaches maintenance levels as the animal matures and thus the retention of $B E$ should approach zero. Setting equation (5) equal to zero and solving with respect to $B W$ yields the following equation, which can be used to calculate the mature $B W$ of an animal based on the estimated parameters of the model

$$
B W_{\max }=\exp \left(\log \left(\frac{\theta_{1}-\theta_{4}}{\theta_{2}}\right) / \theta_{3}\right)
$$

A link function is needed in order to convert the state variable $B E$ into $B W$ and by assuming that the allometric relationship between $B W$ and $B E$ is valid:

$$
B W=\theta_{5} \times B E^{\theta_{6}} \Leftrightarrow B E=\left(\frac{B W}{\theta_{5}}\right)^{1 / \theta_{6}}
$$

From this expression body energy density can be quantified throughout the entire growth period as $M_{t}=B E_{t} / B W_{t}$, which is an indirect measure of the fatness of the animal. Different animals at the 
same $B W$ can have different $B E$ contents, which would reflect variation in the ratio of lean to adipose tissue mass.

We differentiate (7) with respect to $B E$

$$
\frac{d B W}{d B E}=\theta_{5} \times B E^{\theta_{6}-1} \times \theta_{6}
$$

and apply the chain rule to get

$$
\frac{d B W}{d t}=\frac{d B W}{d B E} \times \frac{d B E}{d t}=\left(\theta_{5} \times B E^{\theta_{6}-1} \times \theta_{6}\right) \times\left(\left(\theta_{1}-\theta_{4}\right) \times B W^{\theta_{3}}-\theta_{2} \times B W^{2 \times \theta_{3}}\right)
$$

However, $B E$ is a latent state variable because the energy content of the animal was measured only once, i.e. after slaughter. Therefore further manipulations of (9) are needed for parameter estimation, which can be done by substituting (7) into (9). The manipulations produce two differential equations:

$$
\begin{aligned}
& \frac{d N E}{d t}=\theta_{1} \times B W^{\theta_{3}}-\theta_{2} \times B W^{2 \times \theta_{3}}, N E(0)=N E_{0} \\
& \frac{d B W}{d t}=\theta_{5} \times\left(\frac{B W}{\theta_{5}}\right)^{\theta_{6}-1} \theta_{6} \times \theta_{6} \times\left(\left(\theta_{1}-\theta_{4}\right) \times B W^{\theta_{3}}-\theta_{2} \times B W^{2 \times \theta_{3}}\right), B W(0)=B W_{0}
\end{aligned}
$$

The parameter vector $\theta=\left(\theta^{*}{ }_{1}, \theta^{*}{ }_{2}, \theta_{3}, \theta_{4}, \theta_{5}, \theta_{6}\right)^{T}$ is to be estimated from data and the initial values $y_{0}=\left(N E_{0}, B W_{0}\right)$ are obtained by using the measurements at $\mathrm{t}=0$ as starting values for the filtering and estimation procedures. We investigate if the parameter $\left(\theta_{3}\right)$ can be fixed at 0.75 because this is the traditional scaling factor applied in energy metabolism studies. This in turn makes it easier to compare the estimated maintenance requirement with published values. A complete list of all the parameters, their physical interpretation as well as dimensions is presented in Table 2.

Insert Table 2.

\subsection{The stochastic growth model}

Two sources of variation are considered in the model: 1) a dynamic noise term, which is part of the system (the animal) such that the value of the process at time $t$ depends on this noise up to the time $\mathrm{t}$, and 2) a measurement noise term, which does not affect the process itself, but only its observations. Separation of intra animal variation into two noise components requires additional 
explanation. The system noise can be thought of as animal intrinsic variability due to the following; 1) animal growth is always embedded in a randomly varying environment (no matter how well the experimental conditions are controlled), 2) growth processes are subjected to external and internal influences that change over time (e.g. shifting diets, sub-clinical diseases, ambient temperatures, hormonal influences, emotional stress etc.) which may randomly affect the growth. Modelling all of these aspects that disturb the system would produce a very large and complicated model that renders model identifiability and parameter estimation given data. In the foregoing section, we derived an ODE model based on biological assumptions regarding intake and growth. It is now translated into a stochastic state space model. Thus, the equations governing the growth and intake processes can be written as the following continuous-discrete time state-space model where the two system equations are:

$$
\left(\begin{array}{c}
d N E \\
d B W
\end{array}\right)=\left(\begin{array}{c}
\theta_{1} \times B W^{\theta_{3}}-\theta_{2} \times B W^{2 \times \theta_{3}} \\
\theta_{5} \times\left(\frac{B W}{\theta_{5}}\right)^{\frac{\theta_{6}-1}{\theta_{6}}} \times \theta_{6} \times\left(\left(\theta_{1}-\theta_{4}\right) \times B W^{\theta_{3}}-\theta_{2} \times B W^{2 \times \theta_{3}}\right)
\end{array}\right) d t+\left(\begin{array}{cc}
\sigma_{N E} & 0 \\
0 & \sigma_{B W}
\end{array}\right) d w_{t}
$$

The first term on the right hand side of (11) is commonly called the drift term and the second is commonly called the diffusion term in which $\sigma_{N E}$ and $\sigma_{B W}$ are diffusion coefficients and $w_{t}$ is a two dimensional Wiener process with independent increments. The two measurement equations can be written as:

$$
\left(\begin{array}{l}
y_{1, k} \\
y_{2, k}
\end{array}\right)=\left(\begin{array}{l}
N E_{t_{k}} \\
B W_{t_{k}}
\end{array}\right)+\left(\begin{array}{l}
e_{1, k} \\
e_{2, k}
\end{array}\right)
$$

The observation equations describe what is actually measured at discrete time points $t_{k}=\left(t_{0}<t_{1}<\ldots<t_{N-1}<t_{N}\right)$ and $\left[y_{1, k} ; y_{2, k}\right]^{T}$ are functions of the states $\left[N E_{t_{k}} ; B W_{t_{k}}\right]^{T}$ contaminated with Gaussian white noise $\left[e_{1, k} ; e_{2, k}\right]^{T}$ with variances $S_{N E}$ and $S_{B W}$. The system $w_{t}$ and observation noise $e_{k}$ are assumed to be mutually independent. 
Model diagnostics (residual and autocorrelation plots) are employed and visual inspection of the innovations plotted as a function of time is used to pinpoint if variance stabilization is required. It turned out that on the original scale variance was increasing with expected value and it was decided to work with transformed responses (square root or logarithmic) instead. For linear models it is possible to use the Box-Cox transformation approach, i.e. find the optimal (in a likelihood sense) transformation among the power and logarithmic transformations. A similar theory is not available for SDE models. Instead, we used a "transform both-sides" (TBS) approach, i.e. both responses and expected values in the model are transformed using the same transformation. The appealing feature about the TBS approach is that the parameter interpretations are unchanged. More specifically, the ODE system is transformed and then system noise is added to the transformed ODE system. Hence, system noise is assumed to have a constant intensity on the transformed scale. This approach can be generalized to accommodate any type of transformation. We may introduce $z_{t}=h\left(x_{t}\right)$ where $x_{t}$ denotes the model states $(N E$ and $B W)$. If the original ODE (10) is written as $d x_{t}=f\left(x_{t}, t, \theta\right) d t$ then the ODE for the transformed response $h\left(x_{t}\right)=z_{t}$ is obtained by the chain rule:

$$
d z_{t}=h^{\prime}\left(h^{-1}\left(z_{t}\right)\right) \times f\left(h^{-1}\left(z_{t}\right), t, \theta\right) d t
$$

where $h\left(x_{t}\right)$ is the transforming vector function, $h^{\prime}\left(x_{t}\right)$ is the derivative with respect to the states $x_{t}, h^{-}$ ${ }^{l}\left(z_{t}\right)$ is the inverse of $h(\cdot)$, and $f(\cdot)$ is the functional expression for the original ODE system $(10)$. For instance, if $h\left(x_{t}\right)=(\sqrt{N E}, \sqrt{B W})$ then $h^{-1}\left(z_{t}\right)=\left(N E^{2}, B W^{2}\right)$ and $h^{\prime}\left(x_{t}\right)=(1 / 2 \sqrt{N E}, 1 / 2 \sqrt{B W})$.

Using (13) and adding system noise yields the following SDE system

$$
\begin{aligned}
d z_{t}= & \left.\begin{array}{c}
\frac{1}{2 N E} \times\left(\theta_{1} \times B W^{2 \theta_{3}}-\theta_{2} \times B W^{4 \theta_{3}}\right) \\
\frac{1}{2 B W} \times \theta_{5} \times\left(\frac{B W}{\theta_{5}}\right)^{\frac{2\left(\theta_{6}-1\right)}{\theta_{6}}} \times \theta_{6} \times\left(\left(\theta_{1}-\theta_{4}\right) \times B W^{2 \theta_{3}}-\theta_{2} \times B W^{4 \times \theta_{3}}\right)
\end{array}\right) \\
& +\left(\begin{array}{cc}
\sigma_{N E} & 0 \\
0 & \sigma_{B W}
\end{array}\right) d w_{t}
\end{aligned}
$$


The transformed measurements are obtained as the square root of the original and then the additive measurement noise is added on the transformed scale. Visual inspection of the innovations plotted as function of time is used to choose between the two transformations (logarithmic or square root).

\subsection{Parameter estimation}

Given the model structure (11) and (12) approximate maximum likelihood (ML) estimates of the unknown parameters can be determined by finding the parameters $\theta$ that maximize the approximate likelihood function of a given sequence of measurements $Y_{N}=\left(y_{0}, y_{1}, \ldots, y_{N-1}, y_{N}\right)$. The likelihood function can be expressed as the following by conditioning on the observations at time $\mathrm{t}_{0}$ i.e., $y_{0}=\left(y_{1,0} ; y_{2,0}\right)$,

$$
L\left(\theta \mid Y_{N}\right)=p\left(Y_{N} \mid \theta\right)=\left(\prod_{k=1}^{N} p\left(y_{k} \mid Y_{k-1}, \theta\right)\right)
$$

where $p$ denotes the probability density function conditional on the parameters and the previous observations.

Since the SDE in (12) are driven by a Wiener process and since increments of a Wiener process are Gaussian, it is assumed that the conditional densities can be approximated by Gaussian densities, which means that a method based on the so-called extended Kalman filter (EKF) can be applied (Kristensen and Madsen, 2003). The EKF filter is a recursive algorithm. This means that only the estimated state from the previous time step and the current measurement are used to compute the estimate for the current state because the previous state contains all the information up to that time point. The EKF has two distinct phases: predict and update. The predict phase uses the state estimate from the previous time step to produce an estimate of the state at the current time step. In the update phase, measurement information at the current time step is used to refine this prediction to arrive at a new, more accurate state estimate, again for the current time step (see appendix for full details regarding the EKF algorithm).

Assuming a Gaussian density, which is completely characterized by its first and second order moments, the EKF is used because EKF describes the evolution of the first and second 
order moments of the conditional probability densities in terms of ODEs and algebraic equations. In order to formally introduce the assumption of Gaussianity, the following notation is defined

$$
\begin{aligned}
& \hat{y}_{k \mid k-1}=E\left\{y_{k} \mid Y_{k-1}, \theta\right\} \\
& R_{k \mid k-1}=V\left\{y_{k} \mid Y_{k \mid k-1}, \theta\right\} \\
& \hat{e}_{k}=y_{k}-\hat{y}_{k \mid k-1}
\end{aligned}
$$

and the likelihood function is rewritten in the following way:

$$
L\left(\theta \mid Y_{N}\right)=\left(\prod_{k=1}^{N} \frac{\exp \left(-\frac{1}{2} \hat{e}_{k}^{T} R_{k \mid k-1}^{-1} \hat{e}_{k}\right)}{\sqrt{2 \pi \times \operatorname{det}\left(R_{k \mid k-1}\right)}}\right)
$$

The parameter estimates can now be determined by solving the following nonlinear optimisation problem:

$$
\hat{\theta}=\arg \min _{\theta \in \Theta}\left\{-\log \left(L\left(\theta \mid Y_{N}\right)\right)\right\}
$$

where, for each value of $\theta$ in the optimization, $\hat{e}_{k}$ and $R_{k \mid k-1}$, are computed recursively by the EKF.

The estimation scheme has been implemented in the parameter estimation software

Continues Time Stochastic Modelling (CTSM). More details of the parameter estimation, filtering and smoothing are giving in the CTSM User and Mathematics guides (Kristensen and Madsen, 2003).

The growth and energy intake trajectories obtained from the 13 pigs are analysed separately. Population parameter estimates and their standard deviations are then calculated as the average and standard deviation of the 13 individual estimates. This procedure is called a two stage approach (Davidian and Giltinan, 1995).

\section{Results and discussion}

At a preliminary stage initial parameter estimates and their effect on convergence and final parameters estimates were monitored. In general, for all 13 animals in the data set the 
convergence properties of the estimation procedure were good because all estimations converged in less than 150 object function evaluations. The two transforming functions were applied and diagnostic plots were inspected for all 13 animals, which showed that the best variance stabilizing function was the square root. Therefore, the parameter values and likelihood tests presented in the following is based on the square root transformation. The parameters were all estimated by maximizing the likelihood, and the improvement of fit when $\theta_{3}$ was allowed to vary freely compared to being fixed at 0.75 was measured by the likelihood value at convergence. This is presented in Table 3. In ten of the thirteen analysed data sets, the value of $\theta_{3}$ did not deviate significantly from $0.75(\mathrm{p}>0.05)$. As a consequence, $\theta_{3}$ was fixed at 0.75 for all animals in the subsequent analyses. Parameter values for each animal obtained by fitting the model to data is presented in Table 4 together with population averages and coefficient of variation $(\mathrm{CV})$ for the drift part of the model.

Insert Table 3.

Population based methods (mixed models) have been more widely applied in analysis of pig growth (Criag and Schinckel, 2001; Kebreab et al., 2007). It is assumed that all animals follow the same functional form with parameters varying according to multivariate normal distribution. Thirteen animals as available in this data set are too few for application of a population based approach and thus the data from the 13 pigs were analysed separately. Population based methods are especially useful if the population values are of main interest. In the present study, the animal specific values are of primary interest (e.g. comparison with slaughter data), so the data was analysed pig by pig, but a population based analysis would be of interest, too. Such an approach would yield a complete description of the dynamics with animal-to-animal variation described by key structural parameters and the within-animal variation described by a stochastic process. An algorithm for non-linear mixed effects in combination with SDE-models has recently been developed (Mortensen et al., 2007; Mortensen and Klim, 2008), but needs further investigation. Moreover, note that the current model has a two-dimensional response. None of the standard 
software packages, which are usually applied for nonlinear mixed modelling, will fit multivariate response models because these are developed for the univariate case (Pinheiro and Bates, 2000; Littell et al., 2006).

Measures made on the individual animal are likely to be more correlated than measures made on different individuals, and serial autocorrelation is present since measurements made closely in time tend to be highly correlated compared to measures made further distant in time (Sandland and McGilchrist, 1979). An autocorrelation structure is generated "automatically" due to the stochastic process formulation. Moreover, unequally spaced observations do not create a problem because the model is formulated in continuous time. This is an additional advantage compared to application of ARIMA models for modelling correlated residuals. Insert Table 4.

\subsection{Modelling growth and energy intake patterns}

Growth curves and feed intake curves are often represented as a function of age because age can be recorded more easily and more precisely than for instance weight. The parameters $\theta_{1}{ }^{*}\left(\mathrm{BW}\right.$ at maximum rate of intake) and $\theta_{2}{ }^{*}$ (maximum rate of intake) are estimated in the range of $149-281 \mathrm{~kg} \mathrm{BW}$ and 25.7-35.7 MJ NE/day. Our results indicate that the maximum intake was reached at a much later stage in life than usually reported in studies quantifying feed intake (Andersen and Pedersen, 1996; Lorenzo et al., 2003). This is probably caused be the fact that measurements were conducted outside the normal BW range $(20-120 \mathrm{~kg})$. According to the knowledge of the authors there is no information available on patterns of feed intake of pigs beyond $150 \mathrm{~kg} B W$, which excludes the possibility for comparison. However, our results agree very well with the theory proposed by Emmans (1997), which suggests that intake is maximised at about half of the mature size. A prerequisite for the validity of model is of course that the framework is able to describe the observed patterns of intake and growth. Those are presented in Figure 1, for the drift part of the model and the one-step-ahead predictions generated by the EKF together with observed data from two representative pigs in the dataset. In Figure 1 we have plotted $N E, B W$, intake, and 
growth rate against time to show that the model described data well. Taylor (1985) suggested that intake of animals with a large appetite might decline after having reached a maximum. Fowler (1980) found that the daily intake reached a peak at about $120 \mathrm{~kg} \mathrm{BW}$ and then declined to very fluctuating values. The feed intake data presented by Thompson et al. (1996) suggested that the feed intake did not stabilize at 200 days of age. Moreover, large fluctuations in the feed intake during the course of time were observed as well, which corresponds well with the observations reported in this study. A feature of the model is that the rate of intake increases quickly in the early part of the growth period and then plateaus as the pig matures, which is a consequence of the energy being diverted towards maintenance. Moreover, it has the flexibility to identify that rate of intake has a peak and then decreases towards a plateau level, which corresponds to maintenance of body functions at maturity.

Insert Figure 1.

Modelling $B W$ as a function of age requires a four parameter function like the Bridges, generalized Michalis-Menten or Richards functions for adequately describing the growth trajectory of pigs from birth to maturity (Kreab et al., 2007; Strathe et al., submitted). Lorenzo et al., (2003) presented an analysis of linear and nonlinear models and reported that a three parameter logistic function was appropriate for characterizing the pattern of feed intake in pigs. Thus, a total of seven structural parameters are needed when the responses are modelled separately. The proposed bivariate model uses six parameters in its complete form. However, the dimensionless exponent $\theta_{3}$ was fixed 0.75 during parameter estimation and thus restricting the number of free parameters to only five plus optional two initial state parameters. In terms of the number of structural parameters that has to be estimated the bi-variate approach is not much different than modelling the responses separately. However, the proposed framework offers other quantities (maintenance requirement, energy gain) to be derived compared to the traditional analysis of growth and intake, which are usually confined to estimate initial value, maximum value and inflexion points. The modelled 
growth curves presented in Figure 1 have clear sigmoid shapes and their derivatives with respect to time increase in the early part of life towards a maximum and then decrease towards zero.

Figure 2 presents goodness of fit plots. The observed rates of energy intake and $B W$ gain are plotted against the corresponding one-step-ahead predictions generated by the EKF for the 13 animals and the line $\mathrm{Y}=\mathrm{X}$ is also included. The model fits well to the observed data because the model dynamically tracks the fluctuations in the observations. A comprehensive review of Whittemore et al. (2001) concluded that prediction of short time fluctuations in feed intake was difficult, although the information is essential for the practical purposes of pig's day to day nutrition. Thus, application of SDE models may be a way to obtain precise predictions of short time fluctuations in intake and growth rates.

Insert Figure 2.

\subsection{The biological implications of stochasticity}

In Table 5 parameter estimates related to the stochastic part of the model, e.g. diffusion and measurement error terms are presented. First, it should be noted that the estimated system noise was significant at the 5\% level ( $t$-score around 10$)$ for all modelled animals. The magnitude of difference between the system and measurement noise indicates that the measurement error is negligible compared to the system error for most of the pigs. Note however that it is very difficult to distinguish between the two sources of variation, in particular for equidistant observations. For the bodyweight, the total variance of the difference between two consecutive measurements $y_{1,1}$ and $y_{1,2}$ is approximately $\sigma_{B W}^{2} \Delta t+2 S_{B W}$. If $\Delta t$ is the same for all pairs of consecutive measurements, then only the sum, not the two distinct terms is identifiable. The irregular sampling scheme with weekly and bi-weekly sampling improves identification somewhat, but simulations have indicated that there are still problems for this sampling scheme. Still we can conclude that the animal intrinsic variability is more pronounced than the measurement noise, and fitting a model without measurement errors gives very similar results for the fixed effects. This 
suggests that the incorporation of model uncertainty through a diffusion process is successful from both a biological and a statistical point of view.

Insert Table 5.

Previous attempts to model growth and intake processes are based on models, which are solutions to ODEs (France and Thornley, 1984; Lopez et al., 2000). SDE models provide a much more realistic representation of reality than their deterministic counterparts because system noise reflects that we do not have a full understanding of the complex processes, which regulate intake and growth. For this reason, the aim of the current model formulation has been focussed on modelling both the trend of the growth processes and the random fluctuations by means of SDEs. It further implies that an individual animal does not have a fixed growth curve from birth as growth is subjected to disturbances during life time. This can be demonstrated by a simulation study where the mean parameter values for the modelled growth and intake trajectories are used. The mean parameter vector is given as $\theta=\left(\theta_{1}{ }^{*}=221, \theta_{2}{ }^{*}=31.5, \theta_{3}=0.75, \theta_{4}=0.27, \theta_{5}=0.32, \theta_{6}=0.81\right.$, $\left.\sigma_{N E}=0.17, \sigma_{B W}=0.07\right)^{\mathrm{T}}$. An Euler-Maruyama scheme was used with an integration step of 0.5 day (Kloeden and Platen, 1992). The results of the simulation analysis are shown in Figure 3. The figure is organized as follows: plots A and B show the simulated paths of the stochastic growth model along with the mean curves for the stochastic process; plots $\mathrm{C}$ and $\mathrm{D}$ show the derivatives with respect to time in order to display the hypothesis build into the model. In contrast to previously published deterministic approaches (e.g. Lopez et al., 2000) to model growth and intake, the trajectories are not smooth. In fact, a deterministic model assumes that: 1) the mathematical processes generating the observed intake and growth trajectories are smooth (continuous and continuously differentiable) within the considered time frame; 2) the variability of the actual measurements is due to observation error. The present approach results from the hypothesis that the underlying mathematical process is not smooth, but is subjected to random intrinsic perturbations. This system noise represents the complexed effect of many factors, each with a small individual effect, which are not explicitly represented in the deterministic part of the model (the drift term of 
the model). Figure 3 also clearly illustrates the consequence of assuming that the system noise is additive on a square root scale $(N E$ and $B W)$ because once the simulated trajectories are transformed back to the original scale, it can be seen that the fluctuations in the intake process increase as the animal matures. This phenomenon has previously been described for intake (Fowler 1980;

Thompson et al., 1996).

Insert Figure 3.

\subsection{Estimation of maintenance requirement}

Although the functional relationship might look complicated, the model was derived from basic biological ideas and thus biologically relevant results can be extracted from the analysis. A maintenance component is estimated and expressed on a net energy basis. The maintenance component $\theta_{4}$ in the model was estimated to be in the range of $232-303 \mathrm{~kJ} /\left(\right.$ day $\left.\times \mathrm{kg}^{0.75}\right)$ with a mean of $268 \mathrm{~kJ} /\left(\right.$ day $\left.\times \mathrm{kg}^{0.75}\right)$ and a $\mathrm{CV}$ of $8.6 \%$. In net energy systems the maintenance component is usually estimated by regressing the daily energy retention or heat production on daily $M E$ intake, then the intercept represents the maintenance requirement (Just, 1982; Noblet et al., 1994).

Schiemann et al. (1972) estimated the maintenance requirement as $280 \mathrm{~kJ} /\left(\right.$ day $\left.\times \mathrm{kg}^{0.75}\right)$ for barrows at approximately $95-185 \mathrm{~kg} \mathrm{BW}$, whereas Just (1982) estimated $326 \mathrm{~kJ} /\left(\right.$ day $\left.\times \mathrm{kg}^{0.75}\right)$ for growing pigs weighing from 20 to $90 \mathrm{~kg} B W$. The maintenance estimates produced by the present model are on average slightly underestimated compared to those values (Table 4). There are several explanations to this fact: 1) the maintenance requirement was represented by one parameter in the model and it is likely that this representation is to simplistic because the chemical composition of the body, organ size etc. changes during the course of growth (Tess et al., 1984); 2) fasting heat production measurements are usually conducted in the $B W$ range of $20-110 \mathrm{~kg}$ and thus little information is available beyond this point; 3) the net energy contents of the seven diets used in the present study were calculated from dietary characteristics using the method proposed by Just (1982) and Boisen and Fernandez (1997). We will direct focus towards estimating a maintenance 
requirement based on slaughter data because these can be used for validation. According to the definition of $N E$ we may write the following equation:

$$
N E=\Delta B E+N E M=\Delta B E+\int_{0}^{1} q \times B W^{0.75} d t
$$

Where $q$ represents the maintenance requirement and $\triangle B E$ is the measured increment $B E$ from weaning $\left(t_{0}\right)$ to the time of slaughter $\left(t_{1}\right)$. The integral in (21) can be approximated be the trapezium rule, i.e.

$$
N E M \approx \sum_{k=2}^{N}\left(t_{k}-t_{k-1}\right) \times q \times\left(B W_{k-1}^{0.75}+B W_{k}^{0.75}\right) / 2
$$

The relationship between $N E$ and $\triangle B E+N E M$ is shown in Figure 4 . When a q value of $326 \mathrm{~kJ} /\left(\right.$ day $\left.\times \mathrm{kg}^{0.75}\right)$ (Just, 1982) was used in the left plot, $N E$ was overestimated in relation to measured $N E$ intake. In the right plot, a $q$ value was estimated from data by minimizing the weighted least sum of squares so that estimated $N E$ would be in accordance with the measured $N E$ intake. This procedure converged at $261 \mathrm{~kJ} /\left(\right.$ day $\left.\times \mathrm{kg}^{0,75}\right)$ and the results including the line $\mathrm{Y}=\mathrm{X}$ is shown in the right plot in Figure 4. The derived maintenance requirement can be regarded as a population requirement because each point in the graphs corresponds to one animal. This can be compared to the mean maintenance value of $268 \mathrm{~kJ} /\left(\right.$ day $\left.\times \mathrm{kg}^{0.75}\right)$ obtained with the model (Table 4), which indicates that the model predicted a realistic value. Rather than interpreting this as an absolute maintenance value (i.e. fasting heat production), the maintenance parameter should be considered as an apparent maintenance value because it depends upon the net energy system that has been used to calculate the dietary values.

Insert Figure 4.

\subsection{Modelling relation between body energy retention and body weight}

An allometric relationship was chosen to represent the relation between $B E$ and $B W$ due to its biological interpretation. The reciprocal scaled energy density $\theta_{5}$ differed the most 
between animals $\left(0.192-0.641 \mathrm{~kg} / \mathrm{MJ}^{\theta_{6}}\right)$. All parameter estimates of $\theta_{6}(0.730-0.864)$ in the model were less than unity, which means that the derivative with respect to $B E$ is continuously decreasing. This corresponds to increasing energy density of the pig, which is an obvious consequence of the $B E$ gain changing towards lipid accretion as the animal matures. The $B E$ state variable is a latent variable in the model and is therefore eliminated from the differential equations due to the functional relationship between $B E$ and $B W$. However, growth curves were modelled accurately, which means that the model should be able to predict energy retention at various stages of growth. We evaluated the proposed relationship (7) between $B E$ and $B W$ by comparing it with data from the 170 pigs in the serial slaughter experiment. The results are presented in Figure 5 on $\log$ - $\log$ scales where line $\left(\log (B W)=\log \left(\theta_{5}\right)+\theta_{6} \log (B E)\right)$ is added to the plot. The average of the 13 estimates of $\theta_{5}$ and $\theta_{6}$ is used to construct the population relation. In general, the line agrees well with the observed data, which indicates that the pattern of energy gain is reflected in the $N E$ and $B W$ measurements. However, close inspection of Figure 5 also reveals that $B W$ is underestimated for low $B E$ values and overestimated for high $B E$ values. Furthermore, considering that the estimated maintenance level corresponds closely to the data obtained from serial slaughter experiments suggests that the rules for partitioning of net energy for maintenance and energy gain are adequate. Insert Figure 5.

Other functional relationships, like the augmented allometric, have been proposed for relating different body components, and for some datasets they may yield a better fit than the allometric (Schinckel and de Lange, 1996). The estimated standard errors for $\theta_{5}$ were large relative to the estimates for many of the animals, and the correlation between the estimators of $\theta_{5}$ and $\theta_{6}$ was generally large, around 0.8 . This indicates that the estimation procedure has difficulties in identifying and distinguishing these two parameters. An even more flexible function would enhance this problem. The statistical procedure presented here is suited for multi-response modelling (Kristensen and Madsen, 2003) and thus serial measurements of body composition, e.g. ultra sound or computed tomography scans can be directly integrated as well. Adopting multivariate response 
modelling techniques provides the possibility to formulate structural equations that are fitted simultaneously to data. Analysis of energy balance data has also been approached by multivariate techniques and more information can be extracted from such data (van Milgen and Noblet, 1999).

\section{Conclusion}

The focus in the present investigation was to develop a mathematical model for energy intake, body energy accretion and body weight gain. The model is derived from simple biological assumptions and it can be used to study the interplay between net energy intake and body weight gain. The model is based on two coupled differential equations that describe the evolution in energy intake and body weight gain during the life time of animals. Animal intrinsic variability affects intake and growth and is build into the model through a stochastic differential equation approach. Experimental data obtained on growing pigs is used for parameter estimation and verification of the biological significance of the parameter values. We showed that eight parameters quantifies the time trend and variation in the two dimensional outcome, i.e. body weight at maximum rate of intake (149 - $281 \mathrm{~kg})$; maximum rate of intake $(25.7$ - $35.7 \mathrm{MJ} /$ day $)$; metabolic body size exponent (fixed: 0.75 ); the daily maintenance requirement per kg metabolic body size $\left(0.232-0.303 \mathrm{MJ} /\left(\right.\right.$ day $\left.\left.\times \mathrm{kg}^{0.75}\right)\right)$; reciprocal scaled energy density $\left(0.192-0.641 \mathrm{~kg} / \mathrm{MJ}^{\theta_{6}}\right) ; \mathrm{a}$ dimensional exponent, $\theta_{6}(0.730-0.867)$; coefficient for animal intrinsic variability in intake $\left(0.120-0.248 \mathrm{MJ}^{0.5}\right)$ and coefficient for animal intrinsic variability in growth $\left(0.029-0.065 \mathrm{~kg}^{0.5}\right)$. In conclusion, the new mathematical model provides an important alternative to traditional analysis of energy intake and growth curves by treating the animal's response as two dimensional.

\section{References}

Andersen, S., Pedersen, B., 1996. Growth and feed intake curves for group-housed gilts and castrated male pigs. Anim. Sci., 63, 457-464.

ARC. 1981. The nutrient requirements of pigs. Commonwealth Agricultural Bureaux, Slough, UK. 
Boisen S., Fernández J.A., 1997. Prediction of the total tract digestibility of energy in feedstuffs and pig diets by in vitro analyses. Anim. Feed Sci.Technol. 68, 277-286.

Craig, B. A., Schinckel, A.P., 2001. Nonlinear mixed effects model for swine growth. Prof. Anim. Sci. 17, 256-260.

Davidian, M., Giltinan, D., 1995. Nonlinear models for repeated measures data. Chapman \& Hall.

Emmans, G.C., 1997. A Method to Predict the Food Intake of Domestic Animals from Birth to Maturity as a Function of Time. J Theor. Biol., 186, 189-200.

France, J., Thornley, J.H.M., 1984. Mathematical models in agriculture. Butterworths Publishing, London, pp. 335.

Fowler, V. R., 1980. Growth in mammals for meat production. In growth in animals (ed. T. L. J. Lawrence) pp. 249-263. Butterworths, London.

Garcia, O., 1983. A stochastic differential equation model for height growth of forest stands. Biometrics 39, 1059-1072.

Just, A., 1982. The net energy value of balanced diets for growing pigs. Livest. Prod. Sci., 8, 541551.

Kanis, E., Koop, W.J., 1990. Daily gain, food intake and food efficiency in pigs during the growth period. Anim. Prod. 50, 353-364.

Kristensen, N.R., Madsen, H., 2003. Continuous Time Stochastic Modelling - CTSM 2.3. User and Mathematics Guide- Technical University of Denmark, Lyngby, Denmark.

Kloeden, P.E., Platen, E., 1992. Numerical solution to stochastic differential equations. Springer, New York.

Kebreab, E., Schulin-Zeuthen, M., Lopez, S., Soler, J., Dias, R.S., de Lange, C.F.M. France, J., 2007. Comparative evaluation of mathematical functions to describe growth and efficiency of phosphorus utilization in growing pigs. J. Anim. Sci., 85, 2498-2507.

Littell, R.C., Milliken, G.A., Stroup, W.W., Wolfinger, R.D., Schabenberger, O., 2006. SAS System for Mixed Models, Second Edition. SAS Institute Inc, Cary, North Carolina, USA.

Lopez S., France J., Gerrits W.J.J., Dhanoa, M.S., Humphries D.J., Dijkstra J., 2000. A generalized Michaelis-Menton equation for the analysis of growth. J. Anim. Sci., 78, 1816-1828.

Lorenzo, J.B., Roehe, R., Rave, G., Kalm, E., 2003. Comparison of linear and nonlinear functions and covariance structures to estimate feed intake pattern in growing pigs. Livest. Prod. Sci., $82,15-26$.

Mortensen, S.B., Klim, S., Dammann, B., Kristensen, N.R., Madsen, H., Overgaard R.V., 2007. A matlab framework for estimation of NLME models using stochastic differential equations Applications for estimation of insulin secretion rates, J. Pharmacokinet. Pharmacodyn. 34, 623-642. 
Mortensen S., Klim S., 2008. PSM: Non-Linear Mixed-Effects modelling using Stochastic Differential Equations. R package version 0.8-3. http://www.imm.dtu.dk/psm

National Research Council, 1987. Voluntary feed intake in farm animals. National Academic Press, Washington, DC.

National Research Council, 2000. Nutrient Requirements of Beef Cattle: Seventh Revised Edition: Update 2000. National Academic Press, Washington, DC

Nisbet, R.M., Muller, E.B., Lika, K., Kooijman S., 2000. From molecules to ecosystems through dynamic energy budget models. J. Anim. Ecol., 69, 913.

Noblet, J., Fortune, H., Shi, X.S., Dubois S., 1994a. Prediction of net energy value of feeds for growing pigs. J. Anim. Sci., 72, 344-354.

Noblet, J., Shi, X. S., Dubois, S. 1994b. Effect of body weight of the net energy value of feeds for growing pigs. $72,648-657$.

Pinheiro, J., and Bates D.M., 2000. Mixed effects models in S and S-PLUS. Statistics and Computing, Springer, New York, USA.

Sandland, R., McGilchrist, C., 1979. Stochastic growth curve analysis. Biometrics, 35, 255-271.

Schiemann, R., Nehring, K., Hoffmann, L., Jentsch, W., Chudy A., 1972. Energetische Futterbevertung und Energienormen. VEB Deutscher Landwirtschatsverlag, Berlin, Germany.

Schinckel, A.P., de Lange, C.F.M. 1996. Characterization of growth parameters needed as inputs for pig growth models. J. Anim. Sci. 74, 2021-2036.

Taylor St. C. S. 1985. Use of genetic size-scaling in evaluation of animals growth. J. Anim. Sci. (Suppl. 2) 118-143.

Tauson, A.H., Chwalibog, A., Jacobsen, K., Thorbek, G., 1998. Pattern of protein retention in growing boars of different breeds, and estimation of maximum protein retention. Arch. Anim. Nutr., 51, 253-262.

Tess, M.W., Dickerson, G.E., Nienaber, J.A., Ferrell. C.L., 1984. The Effects of Body Composition on Fasting Heat Production in Pigs. J. Anim. Sci., 58, 99-110.

Thompson J.M., Sun, F., Kuczek, T., Schinckel A.P., Stewart, T.S., 1996. The effect of genotype and sex on the patterns of protein accretion in pigs. Anim. Sci. 63, 265-276

van Milgen, J., Noblet J., 1999. Energy partitioning in growing pigs: The use of a multivariate model as an alternative for the factorial analysis. 77, 2154-2162.

Whittemore, C.T., Green, D.M., Knap P.W., 2001. Technical review of the energy and protein requirements of growing pigs: Food intake. Anim. Sci. 73, 3-17.

\section{Appendix - Extended Kalman Filtering}


The approximate maximum likelihood (ML) estimation of parameters in SDEs involves the use of state filtering. Consider the general SDE model with the following system and measurement equation:

$$
\begin{aligned}
& d x_{t}=f\left(x_{t}, t, \theta\right) d t+\sigma(t, \theta) d w_{t} \\
& y_{k}=h\left(x_{k}, t_{k}, \theta\right)+e_{k}, e_{k} \sim N(0, S)
\end{aligned}
$$

The extended kalman filter (EKF) is a set of equations that provides an efficient recursive approach to approximate the conditional distributions with Gaussian distributions of a sequence of measurements $Y_{N}=\left(y_{0}, y_{1}, \ldots, y_{N-1}, y_{N}\right)$. The conditional densities are thus completely characterized by the one-step prediction error $e_{k}$ and the associated one step prediction covariance matrix $R_{k \mid k-1}$ which are then used to construct the likelihood function.

Given the parameters $\theta$, initial states $\hat{x}_{100}=E\left\{x_{0}\right\}$, and initial state covariance $\hat{P}_{t \mid t_{0}}=V\left\{x_{0}\right\}$, the first step of the EKF involves the output predictions equation:

$$
\begin{aligned}
& y_{k \mid k-1}=h\left(\hat{x}_{k \mid k-1}, t_{k}, \theta\right) \\
& R_{k \mid k-1}=C P_{k \mid k-1} C^{T}+S
\end{aligned}
$$

which predict the mean and covariance of the output at time $t_{\mathrm{k}}$ given all past information available at time $\mathrm{t}_{\mathrm{k}-1}$. Here $S$ is the variance of the measurement error and $C$ is the linearization of the measurement equation, i.e.

$$
C=\left.\frac{\partial h}{\partial x}\right|_{x=\hat{x}_{k \mid k-1}}
$$

The second step of the recursions involves the innovation equation:

$$
e_{k}=y_{k}-\hat{y}_{k \mid k-1}
$$

which determines the one-step-ahead prediction residual at time $t_{k}$. The third step of the recursions involves the Kalman gain equation:

$$
K_{k}=P_{k \mid k-1} C^{T} R_{k \mid k-1}^{-1}
$$


This is basically a matrix of weights that determines the degree of updating in the fourth step because updating is based on a compromise between the observation and current model state. In a situation where the model is good, but the observations are dominated by measurement error, the state estimate should rely more on the model as opposed to fitting the observations. On other the hand, if the model is incomplete the states should rely more on the observations than the model. The updating equations are given by:

$$
\begin{aligned}
& \hat{x}_{k \mid k}=\hat{x}_{k \mid k-1}+K_{k} e_{k} \\
& P_{k \mid k}=P_{k \mid k-1}-K_{k} R_{k \mid k-1} K_{k \mid k-1}^{T}
\end{aligned}
$$

where the predicted mean and covariance of the states at time $t_{k}$ are updated based on the observed value via the innovation and the Kalman gain. The fifth and final step of the EKF algorithm involves the state prediction equations:

$$
\begin{aligned}
& \frac{d \hat{x}_{t \mid k-1}}{d t}=f\left(\hat{x}_{t \mid k-1}, t, \theta\right) \\
& \frac{d P_{t \mid k-1}}{d t}=A P_{t \mid k-1}+P_{t \mid k-1} A^{T}+\sigma \sigma^{T}
\end{aligned}
$$

which are solved for $\mathrm{t} \in\left[\mathrm{t}_{\mathrm{k}}, \mathrm{t}_{\mathrm{k}+1}\right]$ in order to predict the state $\hat{x}_{t \mid k}$ and the associated state covariance $P_{t \mid k}$. Since $f(\cdot)$ is a nonlinear function, a local first-order Taylor expansion of $f(\cdot)$ at each sampling time $t_{k}$ is needed to approximate the matrix A i.e.

$$
A=\left.\frac{\partial f}{\partial x}\right|_{x=\hat{x}_{t \mid k-1}}
$$

The new predicted mean and covariance of the states are then used to predict new values for the next observation and thus steps from A.3 to A.12 are repeated. 


\section{Figure legends}

Fig. 1. The relationship between total net energy intake, body weight, net energy intake, growth rate and age of two representative pigs (top: 6206 and bottom: 5374) in the dataset. The circle symbols present the actual measurements where the observational rates were calculated as the mean rates within a given sub-period i.e. $\left(\mathrm{NE}_{2}-\mathrm{NE}_{1}\right) /\left(\mathrm{t}_{2}-\mathrm{t}_{1}\right)$ or $\left(\mathrm{BW} \mathrm{W}_{2}-\mathrm{BW}_{1}\right) /\left(\mathrm{t}_{2}-\mathrm{t}_{1}\right)$. The solid line represents the one-step-ahead prediction generated by the Extented Kalman Filter and the dotted line represents the solutions to the drift term of the model, respectively. 
Fig. 2. Goodness of fit graphs for the 13 pigs. The rates of energy intake and BW gain are plotted against the corresponding one-step-ahead predictions generated by the extended Kalman filter. The solid line represents $\mathrm{Y}=\mathrm{X}$.

Fig. 3. Simulation results of the proposed model. Plots A and B presents three simulated paths and the mean curve for the total net energy intake and body weight for the selected parameters, respectively. Plots $\mathrm{C}$ and $\mathrm{D}$ present the derivative with respect to time for the process and drift term in the model.

Fig. 4. Plot of total net energy intake taken as the sum of body energy and integrated maintenance requirement against measured total net energy intake. The maintenance requirement (left) is 326 $\mathrm{kJ} /\left(\right.$ day $\left.\times \mathrm{kg}^{0.75}\right)$ and (right) $261 \mathrm{~kJ} /\left(\right.$ day $\left.\times \mathrm{kg}^{0.75}\right)$. The solid lines is $\mathrm{Y}=\mathrm{X}$ whereas the dotted (left) is the regression equation $\mathrm{Y}=-310+1.18 \mathrm{X}$.

Fig. 5. Validation of the proposed relationship between body weight and body energy $\left(\log (B W)=\log \left(\theta_{5}\right)+\theta_{6} \log (B E)\right)$. Measurements of body weight are plotted as a function of body energy contents for 170 pigs with the mean estimated relationship (mean of the 13 parameter estimates). 


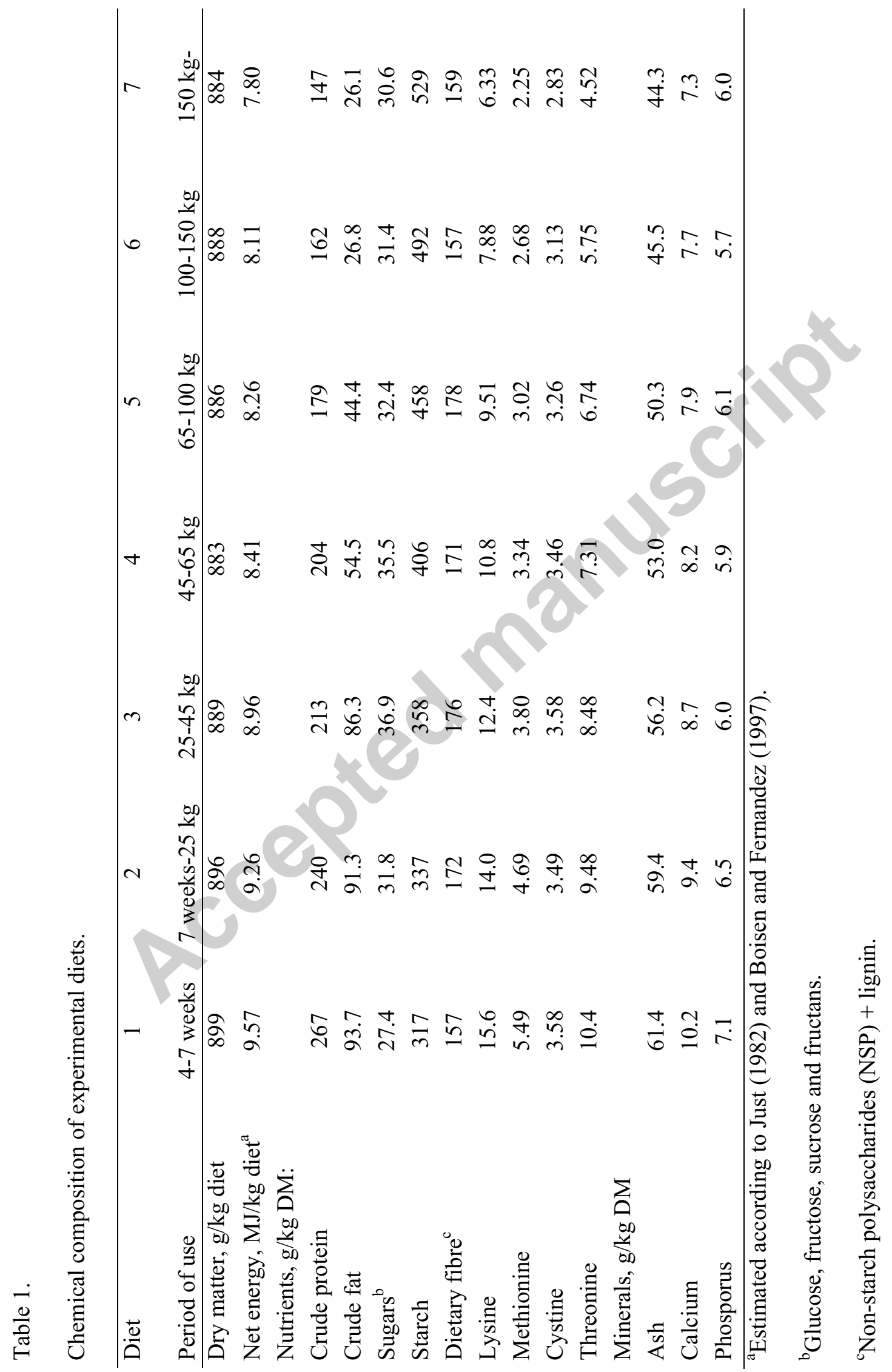


Table 2.

Definitions of model parameters.

\begin{tabular}{lll}
\hline Parameters & Unit & Parameter interpretation \\
\hline$\theta_{1}{ }^{*}$ & $\mathrm{~kg}$ & Body weight at maximum rate of intake \\
$\theta_{2}{ }^{*}$ & $\mathrm{MJ} / \mathrm{day}$ & Maximum rate of intake \\
$\theta_{3}$ & $\mathrm{MJ} /\left(\right.$ day $\left.\times \mathrm{kg}^{\theta_{3}}\right)$ & The daily maintenance requirement per kg metabolic body size \\
$\theta_{4}$ & $\mathrm{~kg} / \mathrm{MJ}^{\theta_{6}}$ & Reciprocal scaled energy density \\
$\theta_{5}$ & & Dimensionless exponent \\
$\theta_{6}$ & $\mathrm{MJ}$ & Diffusion coefficient related to animal intrinsic variability in intake \\
$\sigma_{N E}$ & $\mathrm{~kg}$ & Diffusion coefficient related to animal intrinsic variability in \\
$\sigma_{B W}$ & & growth \\
& & Measurement noise \\
$S_{N E}$ & $\mathrm{~kg}^{2}$ & Measurement noise \\
$S_{B W}$ & &
\end{tabular}


Table 3.

Fit statistics for models $\mathrm{M}_{0}$ (varying $\theta_{3}$ ) and $\mathrm{M}_{1}$ (fixed $\theta_{3}$ ).

\begin{tabular}{lcccc}
\hline Pig & $\operatorname{Logl}_{0}{ }^{\mathrm{a}}$ & $\operatorname{Logl}_{1}{ }^{\mathrm{a}}$ & $\mathrm{LR}^{\mathrm{b}}$ & $\mathrm{p}$-value \\
\hline 5365 & 16.35 & 16.39 & 0.080 & 0.777 \\
5374 & 28.77 & 29.16 & 0.780 & 0.377 \\
5711 & 58.80 & 62.30 & 7.000 & 0.008 \\
5713 & 53.79 & 54.28 & 0.980 & 0.322 \\
5720 & 38.73 & 38.97 & 0.480 & 0.488 \\
6053 & 45.80 & 51.80 & 12.00 & 0.001 \\
6056 & 25.89 & 32.14 & 12.50 & 0.000 \\
6205 & 10.69 & 11.97 & 2.560 & 0.110 \\
6206 & -7.178 & -7.155 & 1.250 & 0.264 \\
6211 & 20.60 & 20.83 & 0.460 & 0.498 \\
6710 & -0.270 & 0.815 & 2.170 & 0.141 \\
6713 & 22.57 & 23.27 & 1.400 & 0.237 \\
6716 & 18.86 & 19.76 & 1.800 & 0.180 \\
\hline$L 0 g-16$ & & & \\
\hline
\end{tabular}

${ }^{\mathrm{a}} \mathrm{Log}$-likelihood value at final convergence for the models.

${ }^{\mathrm{b}}$ Likelihood ratio for comparison of the two models $\mathrm{M}_{0}$ and $\mathrm{M}_{1}$.

${ }^{\mathrm{c}}$ The corresponding $\mathrm{p}$-value in the chi-squared distribution with one degree of freedom. 
已

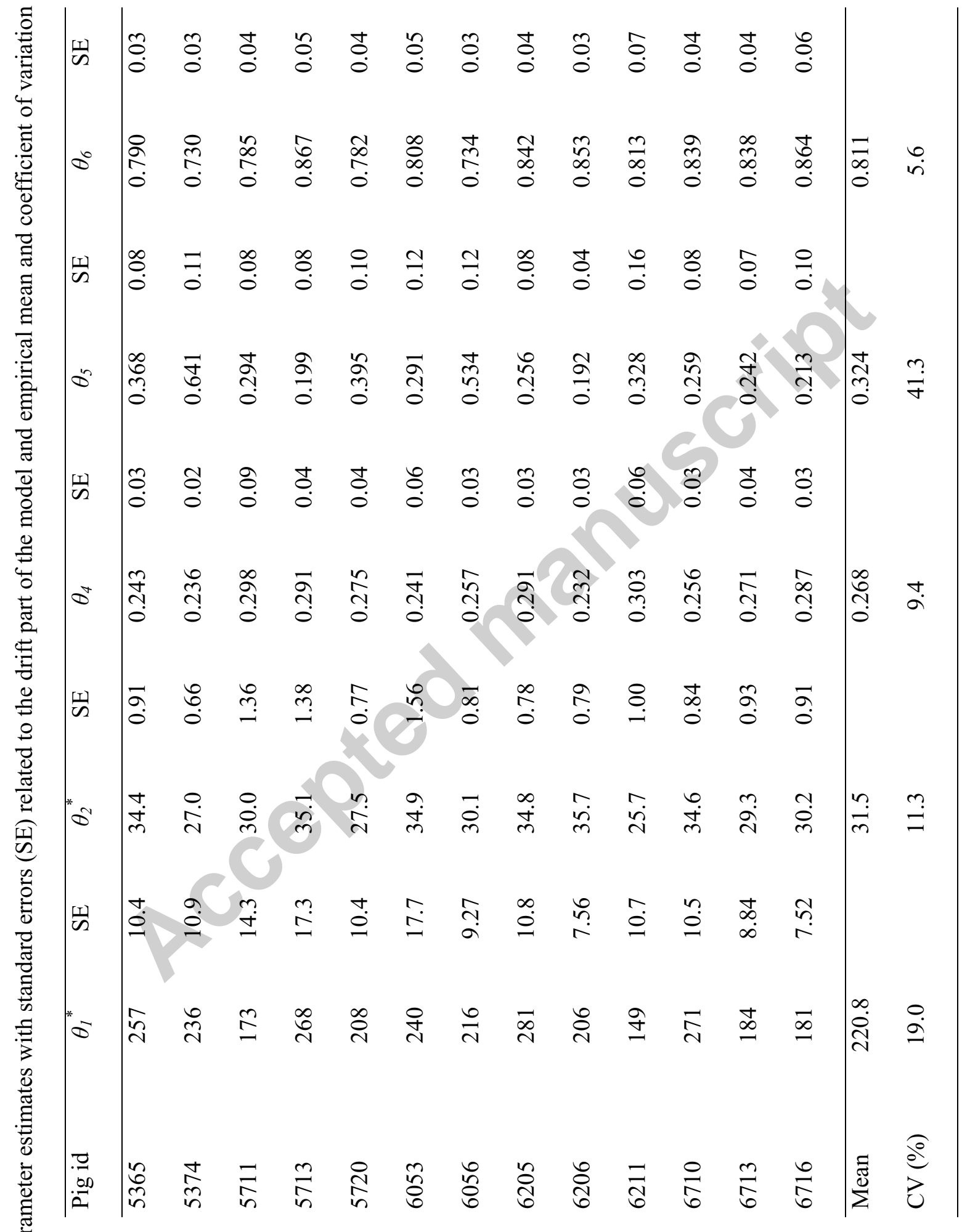


Table 5.

Parameter estimates related to the stochastic part of the model.

\begin{tabular}{|c|c|c|c|c|}
\hline Pig & $\sigma_{\mathrm{NE}}$ & $\sigma_{\mathrm{BW}}$ & $\mathrm{S}_{\mathrm{NE}}$ & $\mathrm{S}_{\mathrm{BW}}$ \\
\hline 5365 & 0.152 & 0.048 & 0.000 & 0.000 \\
\hline 5374 & 0.124 & 0.036 & 0.014 & 0.015 \\
\hline 5711 & 0.248 & 0.060 & 0.098 & 0.000 \\
\hline 5713 & 0.206 & 0.060 & 0.025 & 0.003 \\
\hline 5720 & 0.157 & 0.053 & 0.000 & 0.008 \\
\hline 6053 & 0.239 & 0.065 & 0.000 & 0.000 \\
\hline 6056 & 0.143 & 0.035 & 0.003 & 0.016 \\
\hline 6205 & 0.120 & 0.052 & 0.000 & 0.000 \\
\hline 6206 & 0.132 & 0.029 & 0.023 & 0.001 \\
\hline 6211 & 0.190 & 0.057 & 0.009 & 0.000 \\
\hline 6710 & 0.131 & 0.041 & 0.000 & 0.001 \\
\hline 6713 & 0.173 & 0.050 & 0.000 & 0.000 \\
\hline 6716 & 0.165 & 0.054 & 0.000 & 0.000 \\
\hline Mean & 0.168 & 0.049 & 0.013 & 0.003 \\
\hline $\mathrm{CV}(\%)$ & 25.1 & 22.4 & 205 & 170 \\
\hline
\end{tabular}



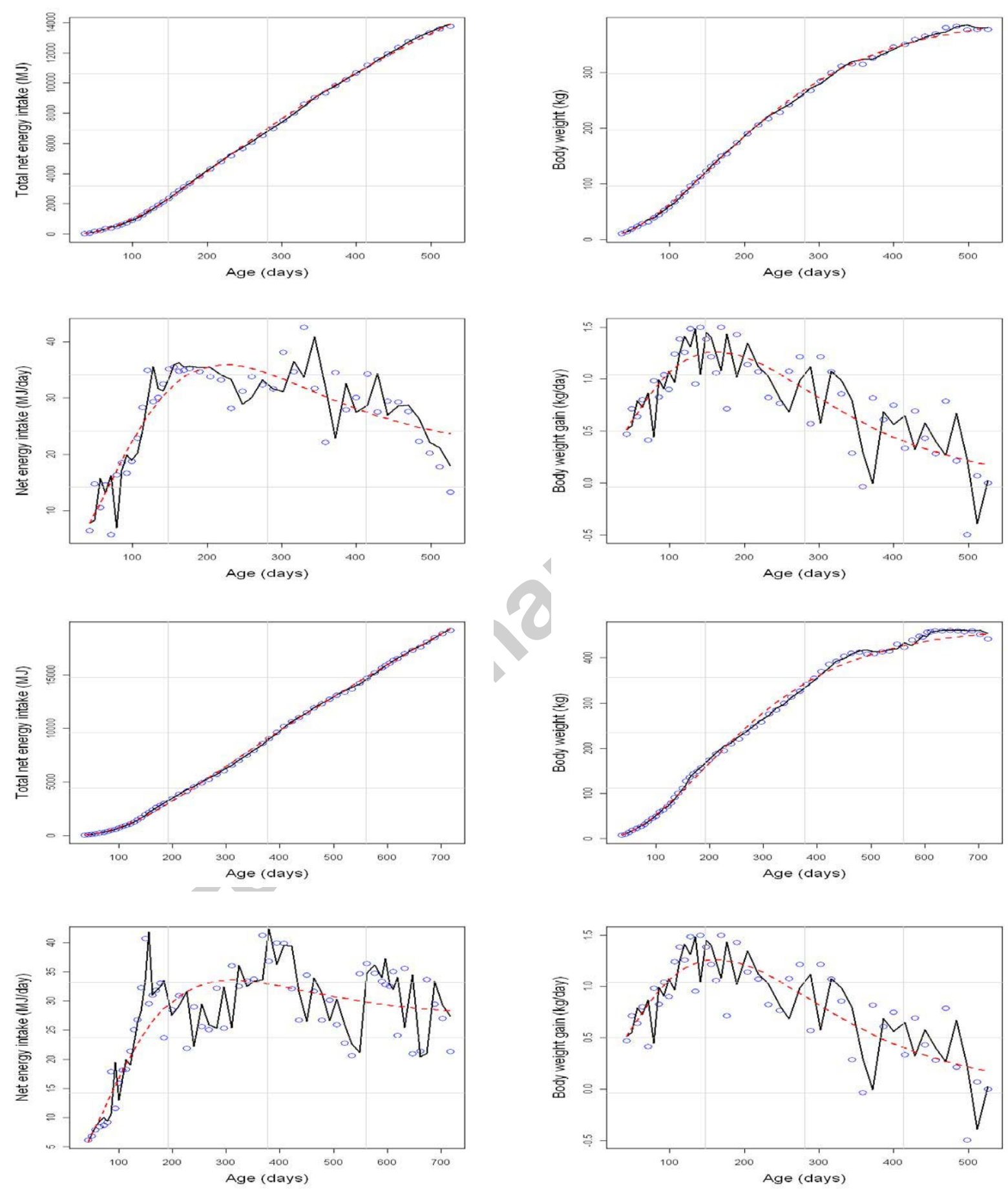

Figure 1. 

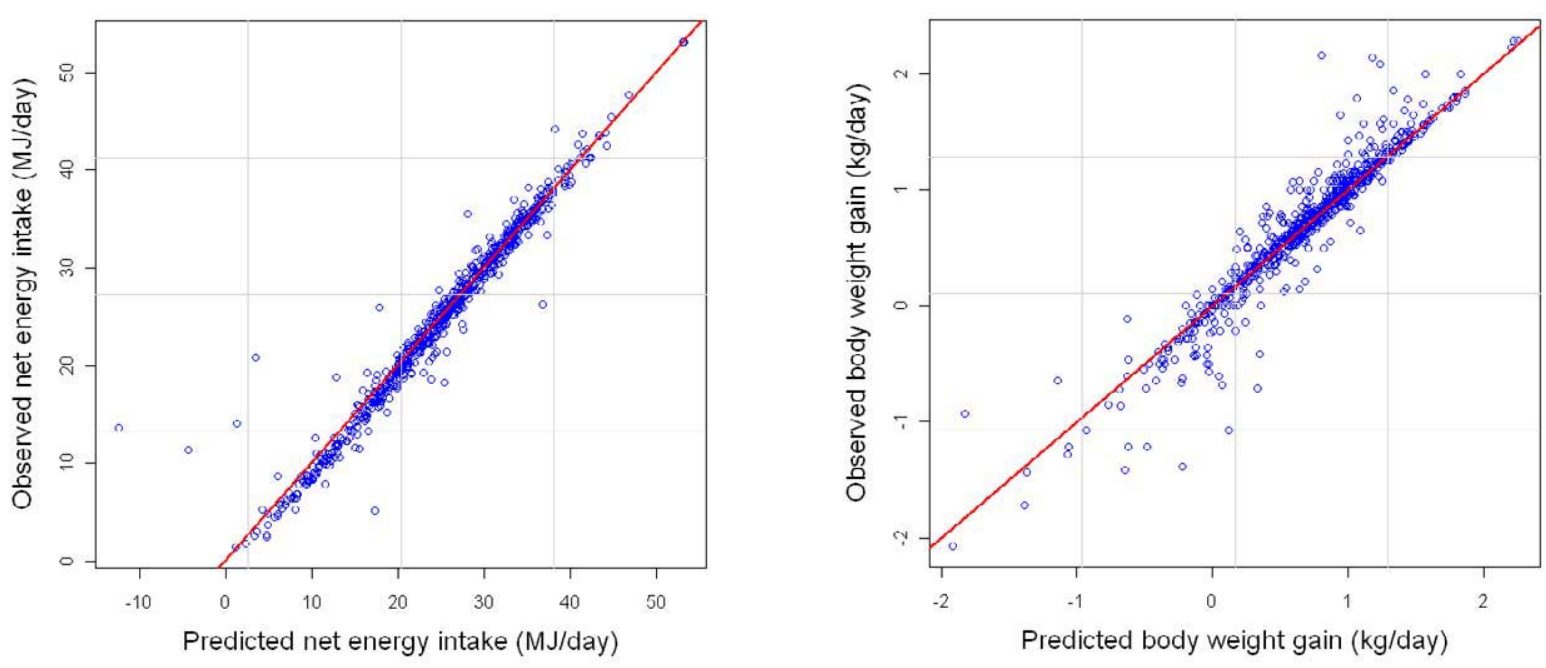

Figure 2. 


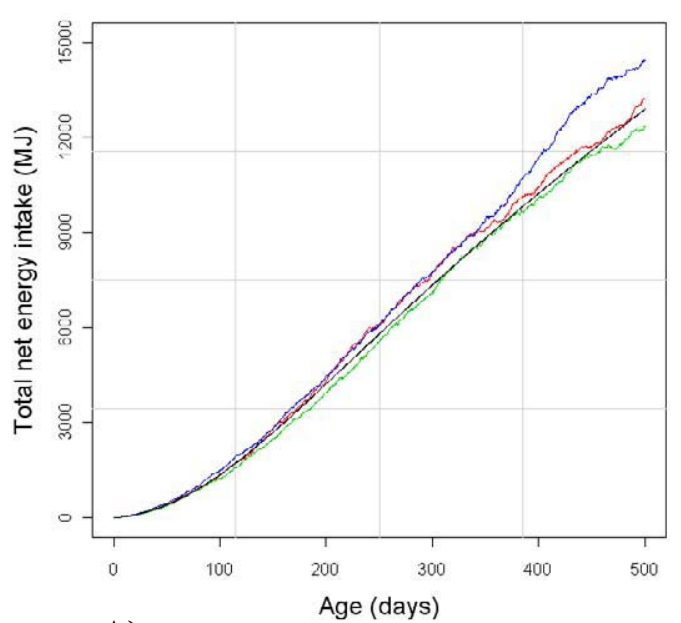

A)

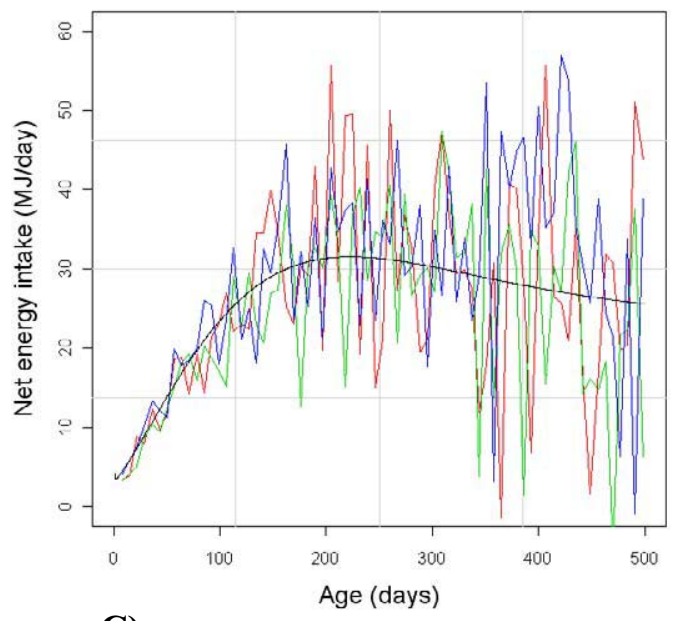

C)

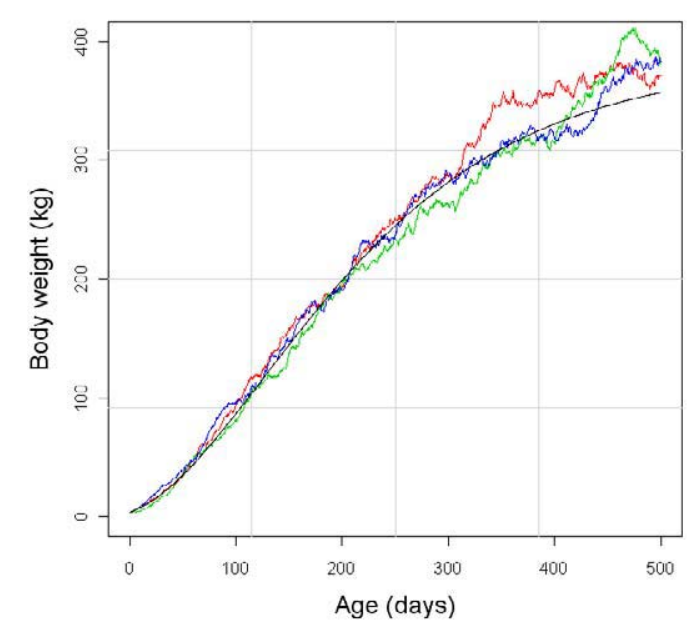

B)

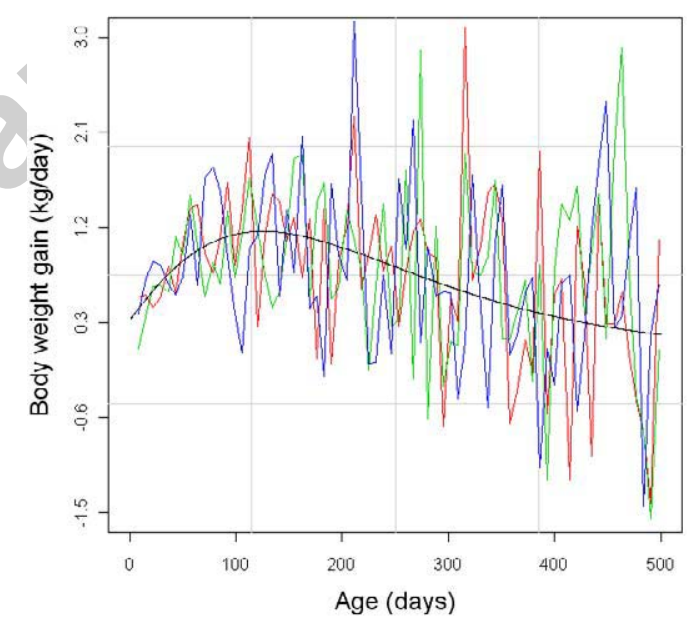

D)

Figure 3. 

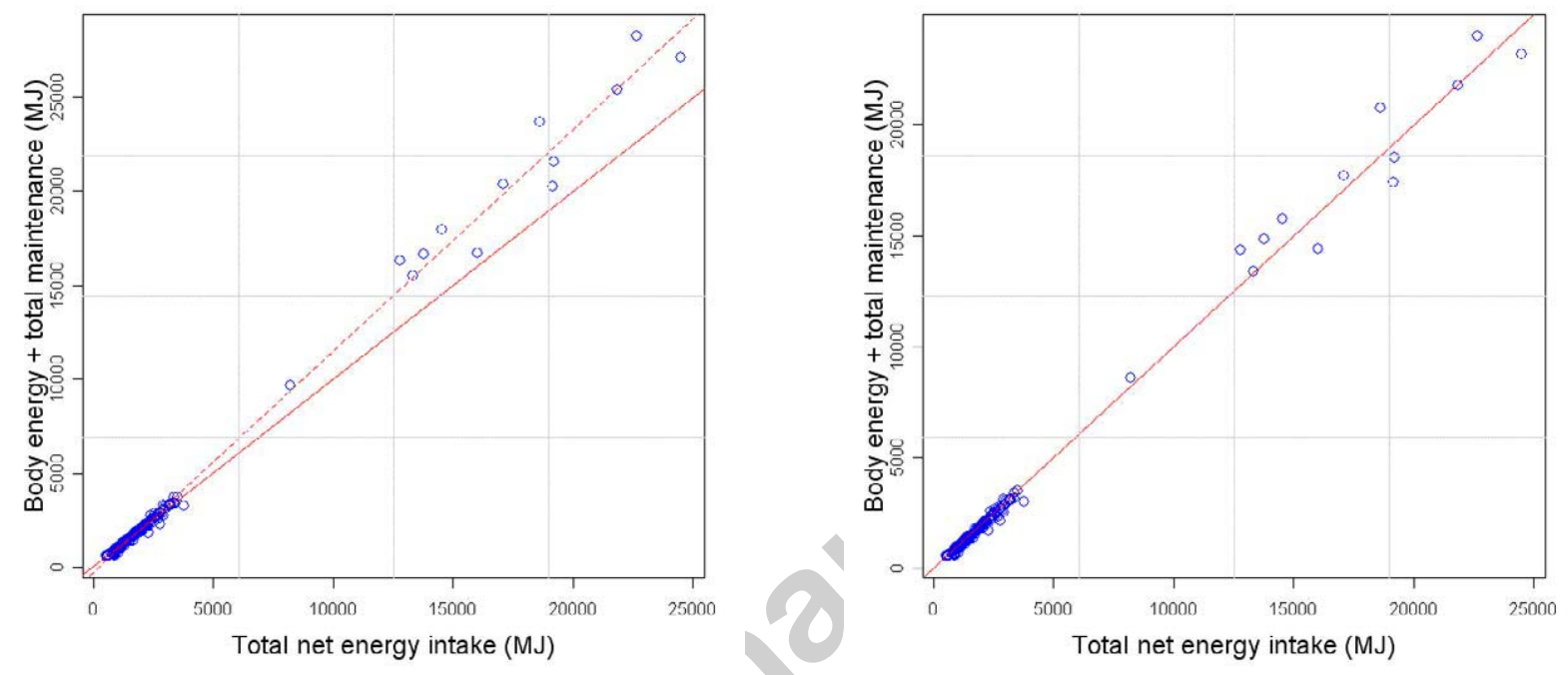

Figure 4. 


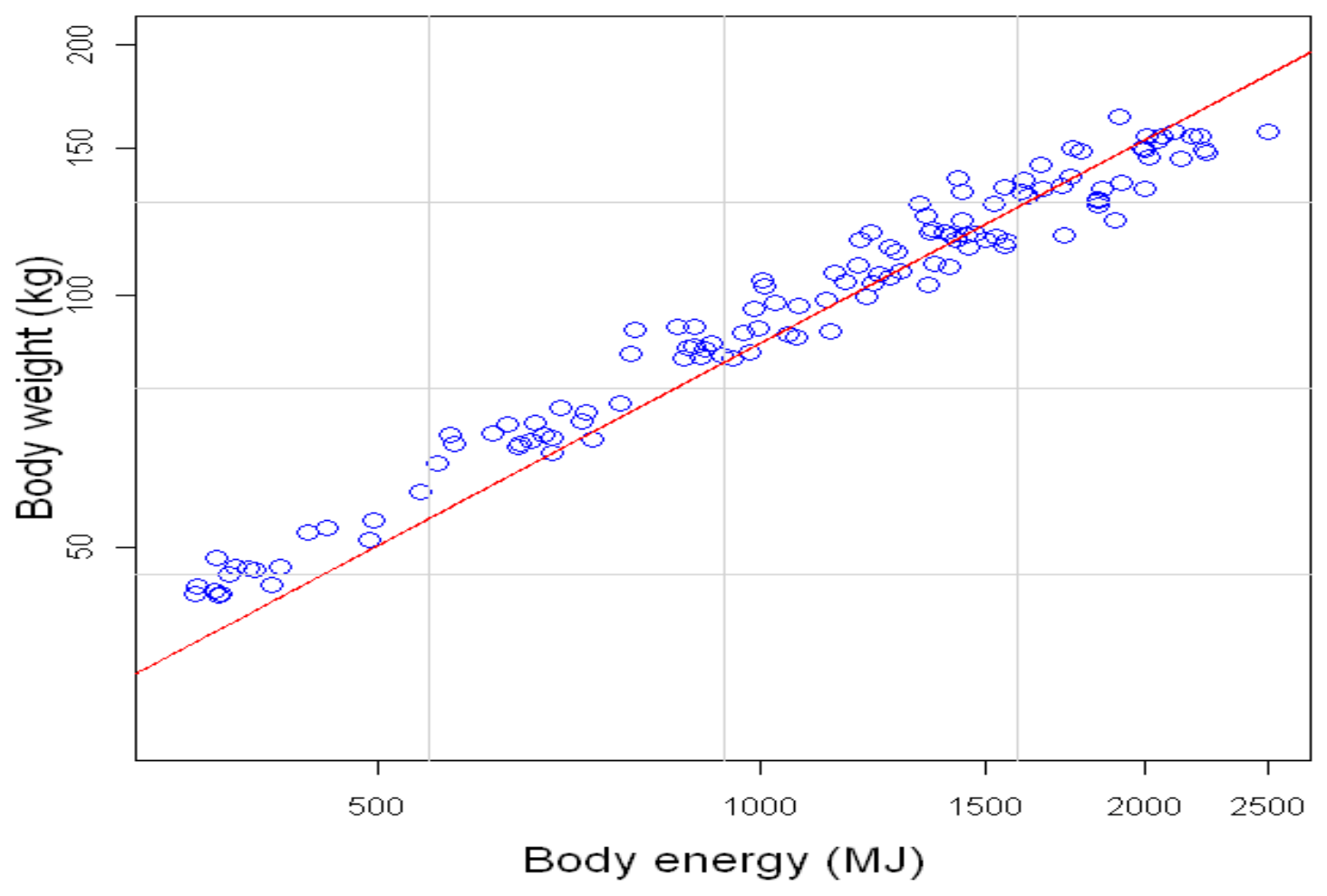

Figure 5. 